\title{
Resolução Consensual de Conflitos e o Atual Código de Processo Civil: Mediação e Conciliação
}

\section{Consensual Conflict Resolution and the Current Civil Procedure Code: Mediation and Conciliation}

\author{
Anderson Vargas ; Luis Gustavo Liberato Tizzo ${ }^{\mathrm{ab}}$

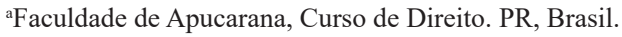

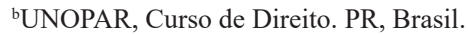 \\ *E-mail:
}

\begin{abstract}
Resumo
Este trabalho pretende discutir sobre os métodos de resolução de conflitos presentes no atual Código de Processo Civil, com um foco maior nos institutos da mediação e conciliação. O estudo do conceito de mediação e conciliação traz a cidadania e a busca pela pacificação social pelos próprios envolvidos dos conflitos. O Conselho Nacional de Justiça e as legislações pertinentes tem buscado meios para um desafogamento do Poder Judiciário, porém muito mais do que buscar uma celeridade na solução dos processos, busca-se a pacificação social entre as partes de um conflito. A conciliação estava presente nos procedimentos judiciais, já a mediação, passa a ser mais presente, diante de sua institucionalização no Código de Processo Civil promulgado em 2015. Nesse trabalho demonstra a necessidade de mudança de cultura da sociedade e para que essa mudança ocorre o Poder Judiciário deve se reinventar e levar a sociedade as vantagens de resolver o conflito pela autocomposição entre as partes.
\end{abstract}

Palavras-chave: Código Processo Civil. Mediação. Conciliação. Autocomposição

\begin{abstract}
This paper aims to discuss the methods of conflict resolution present in the current Civil Procedure Code, with a greater focus on the institutes of mediation and conciliation. The study of the concept of mediation and conciliation brings citizenship and the search for social pacification by those involved in the conflicts themselves. The National Council of Justice and the pertinent legislations have been looking for means for the Judiciary to be released, but much more than seeking speed in the solution of the processes, the social pacification between the parties of a conflict is sought. Conciliation was present in judicial proceedings, while mediation is now more present, given its institutionalization in the Civil Procedure Code promulgated in 2015. This work demonstrates the need for a change in society's culture and for this change to occur the judiciary must reinvent itself and bring society the advantages of resolving the conflict through self-composition between the parties.
\end{abstract}

Keywords: Civil Procedure Code. Mediation. Conciliation. Self Composition

\section{Introdução}

É inquestionável as mudanças que vem acontecendo no Poder Judiciário Brasileiro, desde da promulgação da Constituição Federal Brasileiro de 1988 (BRASIL, 1988), o judiciário tem buscado métodos de solução de conflitos que possam humanizar o atendimento à população e tornar mais célere a atuação do judiciário. Necessita-se aprimorar e ampliar as formar de acesso à justiça diante da demora do tradicional método processual. O Poder Judiciário está superlotado de processos, e nada mais adequado ao momento, que estimular múltiplas opções de resolução de conflitos de forma extrajudicial e judicial, de preferência mais próximas da própria sociedade, o que é o caso do instituto da mediação e da conciliação, que será tratada nesse estudo.

Será abordado nesse estudo dois métodos presentes no atual Código de Processo Civil, a mediação e a conciliação. A mediação e conciliação são técnicas destinadas a solucionar conflitos entre as partes. O objetivo principal é expandir a comunicação entre os envolvidos, de forma a permitir uma troca positiva de ideias e opiniões entre as partes, que tornem possível o acordo.

A mediação e conciliação são institutos que são muitos parecidos, porém o Código de Processo Civil trouxe a melhor aplicação de cada técnica. A conciliação, será aplicada, preferencialmente, nos casos onde não houve vínculo anterior entre as partes, como no caso de acidentes de trânsito. A mediação deverá ser aplicada, preferencialmente, nos casos onde há um vínculo entre as partes envolvidas do litígio.

É necessária mudança de comportamento entre todas as partes envolvidas, como: operadores do direito, mediadores/ conciliadores e a sociedade, permitindo mudança cultural sobre a solução de conflitos, através de informação a respeito dos meios alternativos de conflitos. A conciliação e a mediação apresentam-se como dois importantes meios de tratamento de Conflitos, sendo sempre importante relembrar que o objetivo principal do processo é muito mais do que a celeridade processual, mas sim a efetividade da pacificação social. 


\section{Desenvolvimento}

\subsection{Métodos alternativos de solução de conflitos}

Há diversos termos para esse recorrente fenômeno nas relações pessoais, a expressão "conflito" costuma ser usada como sinônimo de "controvérsia", "disputa", "lide" e "litígio". O conflito pode ser visto como uma crise na interação entre as pessoas (TARTUCE, 2019).

Os métodos alternativos de solução de conflitos, conhecidos por sua sigla em inglês como Alternative Dispute Resolution - ADR, sendo formas de solucionar os conflitos com ou sem da participação da Justiça estatal (PUCCI, 1997), que são as quais realçam a preocupação dos juristas modernos na utilização destes meios alternativos, outros caminhos, outras opções, para obtenção de redução de controvérsias com maior agilidade, economia e confidencialidade da que se obteria recorrendo à Justiça Pública.

O Poder Judiciário finalizou o ano de 2018 com 78,7 milhões de processos em tramitação, aguardando alguma solução definitiva, segundo Justiça em Números 2019 divulgados pelo Conselho Nacional de Justiça (CNJ, 2019a). Desses, 14,1 milhões, ou seja, 17,9\% estavam suspensos, sobrestados ou em arquivo provisório, aguardando alguma situação jurídica futura. Dessa forma, desconsiderados tais processos, tem-se que, em andamento, ao final do ano de 2018 existiam 64,6 milhões ações judiciais.

A conciliação, política permanente do CNJ desde 2006, apresenta lenta evolução, em 2018 foram 11,5\% de processos solucionados via conciliação. Apesar de o novo Código de Processo Civil, tornar obrigatória a realização de audiência prévia de conciliação e mediação, em três anos o índice de conciliação cresceu apenas 0,5 ponto percentual. $\mathrm{O}$ dado positivo é o crescimento na estrutura dos CEJUSCs em 66,4\% em três anos - em 2015 eram 654 e em 2018, 1.088 (CNJ, 2019a).

Os métodos de solução de conflitos elencados no atual Código de Processo Civil têm como objetivo principal diminuir a demanda do judiciário e alcançar um nível de celeridade e efetividade processuais até então desconhecido dos órgãos judiciários.

\subsection{Princípios Constitucionais}

Os princípios constitucionais têm o objetivo/devem de promover meios para garantir a mobilidade e acessibilidade efetiva do cidadão aos variados serviços, entre eles o judiciário, reduzindo distâncias de uma solução célere e acessível os indivíduos, sendo que os métodos de solução de conflitos têm o objetivo de atender esses princípios. Como órgão e poder que integra o Estado, o Judiciário tem o compromisso de garantir, com independência, o cumprimento da Constituição e as leis do país.

Comenta Guerrero (2019) que na Constituição Federal do Brasil em vigor, os métodos adequados ou alternativos de solução de controvérsias, ou MASCs, retomam papel de destaque para aplicação no âmbito do direito interno e privado. O art. 114, da CFB/88 (BRASIL, 1988), prevê a utilização de negociação coletiva e de arbitragem para conflitos coletivos. Ademais, não se pode esquecer de que o preâmbulo da Constituição indica o Brasil um Estado Democrático e comprometido na ordem interna e internacional, com a solução pacífica das controvérsias.

$\mathrm{O}$ acesso à ordem jurídica justa é visto como um instrumento ético para a realização da justiça. Tendo em vista o direito fundamental de acesso à Justiça assegurado pelo art. $5^{\circ}$, XXXV, da Constituição Federal (BRASIL, 1988), o pelo art. $3^{\circ}$ do Código de Processo Civil dispõe que não se excluirá da apreciação jurisdicional ameaça ou lesão a direito.

$\mathrm{O}$ acesso à Justiça trata-se do princípio essencial ao funcionamento do Estado de direito. Isso porque um Estado estruturado sob esse postulado deve garantir, na sua atuação por completo de um sistema judiciário, com isonomia substancial aos cidadãos. Na função jurisdicional, esse dever de igualdade se expressa, precisamente, pela garantia de acesso à Justiça (PINHO, 2019).

A Emenda Constitucional $n^{\circ} 45 / 2004$, denominada de Reforma do Judiciário, em seu artigo $1^{\circ}$, ao acrescentar ao artigo $5^{\circ}$ da Constituição Federal, o inciso LXXVIII, garante a todos, no âmbito judicial e administrativo, são assegurados a razoável duração do processo e os meios que garantam a celeridade de sua tramitação.

Com a positivação contida no art. $5^{\circ}$, LXXVIII, tornandose induvidoso que o direito do cidadão ao processo, como método presente do conflito de interesses qualificado por uma pretensão resistida, passou a ser recepcionado como um direito subjetivo constitucional, que poderá levar o Estado a indenizar pelo atraso injustificado da prestação jurisdicional.

A Convenção Americana de Direitos Humanos (CONFERÊNCIA, 1992), Pacto de São José da Costa Rica, no art. 8,1 , prevê que toda pessoa tem o direito a ser ouvida com as devidas garantias e dentro de um prazo razoável, por um juiz ou tribunal competente, independente e imparcial, estabelecido anteriormente por lei.

A dignidade do ser humano é baseada na direção autônoma do seu comportamento, no compromisso que possui com suas deliberações e seus atos, no guiar a sua vida com base em seus valores e convicções. A não pressuposição do homem com tais características é uma invalidação de toda linguagem moral.

Segundo Pinho (2019) o processo é o instrumento pelo qual o Estado confere a decisão na solução de conflitos e isso deve ocorrer de maneira justa. Dentro desse modelo, surgiu no direito pátrio o chamado processo justo, que refere $\square$ se ao ideal de que o processo seja formado em concordância com os preceitos de dignidade da pessoa humana.

Tartuce (2019) afirma que, a dignidade é princípio da República e ícone entre os direitos fundamentais. No mundo do Direito, sua representação é árdua, visto que o vazio da expressão acaba por torná-la um verdadeiro enigma, que pode 
forçar uma submissão do Direito a padrões inversos à própria dogmática jurídica.

\subsection{Conciliação e mediação}

Na perspectiva de Celant (2015) os métodos consensuais de Solução de Conflitos, a Mediação e a Conciliação, descritos no vigente Código de Processo Civil, permitem que as pessoas tomem suas próprias decisões de forma autônoma e responsável, em vez de derivar da decisão proferida na figura do Magistrado.

A Mediação e a Conciliação permitem não apenas a resolução dos conflitos, mas a pacificação dos mesmos por meio da resolução dos próprios envolvidos no litígio. Assim, podendo que os mesmos de exercerem sua cidadania plena por meio de sua própria capacidade de resolução das próprias controvérsias (BRAGA NETO, 2007).

Há muita confusão sobre os dois institutos, mediação e conciliação, Tartuce (2019) faz alguns apontamentos de pontos comuns à mediação e à conciliação: 1. A participação de um terceiro imparcial; 2. A promoção da comunicação entre os envolvidos; 3. A não imposição de resultados; 4. O estímulo à busca de saídas pelos envolvidos e 5 . O exercício da autonomia privada na elaboração de opções para os impasses.

Além de estabelecer a tentativa de composição da lide como o primeiro ato do procedimento comum, o atual Código de Processo Civil, disciplina em uns dos seus princípios a promoção da solução consensual dos conflitos como princípio fundamental do processo civil, descrito no art. $3 .^{\circ}, \S \S 2 .^{\circ}$ e $3 .^{\circ}$ e dedica à matéria uma seção específica sobre a mediação e conciliação entre os artigos 165 a 175.

A mediação e conciliação sempre aparecem juntas no Código de Processo Civil, pois só no caso concreto é possível determinar qual será aplicada com mais eficácia e eficiência. A audiência de conciliação ou de mediação é designada pelo juiz no despacho da petição inicial, sempre que ela preencher os requisitos necessários para a devida aplicação da conciliação ou mediação. Para participar da audiência, o réu será citado com pelo menos vinte dias de antecedência como determina o artigo 334, caput, do CPC (BRASIL, 2016).

Tartuce (2019) ensina que a conciliação e mediação é naquela na qual o terceiro imparcial, mediante atividades de escuta e investigação, auxiliando as partes a celebrarem um acordo, até mesmo expondo pontos fortes e fracos de suas posições e propondo acordo.

Em relação à busca de meios que sanem efetivamente as controvérsias, é inegável a evolução normativa no cenário brasileiro se deu com a Resolução no 125 de 2010 do Conselho Nacional de Justiça - CNJ, normativo com importante papel desde que instituiu da Política Judiciária Nacional de tratamento adequado de conflitos, criando melhores bases para o desenvolvimento da conciliação e da mediação no âmbito judiciário, preceitua Tartuce (2019).

\subsection{Conciliação mediação no atual Código de Processo Civil}

O Código de Processo Civil é o conjunto de regras que regulam a prestação da atividade jurisdicional pelo Estado, sendo essa uma das formas possíveis de solução de Conflitos.

Para Almeida, Pantoja e Pelajo (2016) se faz necessário, regredir e entender os diversos métodos de solução de conflitos com clareza para compreender o conteúdo e a extensão que se deve atribuir aos artigos do atual Código de Processo Civil.

Para Guilherme (2018), o atual Código de Processo Civil, que começou sua vigência no ano recente ano de 2015, significou grande avanço para a comunidade jurídica no Brasil, principalmente um passo importante para a sociedade civil, que necessitava de uma norma eficiente que disciplinasse as principais alterações sociais e instrumentais.

O Código de Processo Civil trata, por exemplo, da autocomposição, regulando a mediação e a conciliação nos arts. 165 a 175, inserindo a tentativa de autocomposição como ato anterior à defesa do réu nos arts. 334 e 695, permitindo, no acordo judicial, a inclusão de matéria estranha ao objeto litigioso do processo no art. 515, $\$ 2^{\circ}$ e admitindo acordos sobre o processo em seu art. 190.

Os meios consensuais, conciliação e mediação, foram explicitados como diretriz essencial do Código de Processo Civil, no art. 3. ${ }^{\circ}, \S 2 .^{\circ}$, traz em sua redação que o Estado promoverá, sempre que possível, a solução consensual dos conflitos e no art. $3^{\circ}, \S 3^{\circ}$, trazendo a redação que a conciliação, a mediação e outros métodos de solução consensual de conflitos deverão ser estimulados por juízes, advogados, defensores públicos e membros do Ministério Público, inclusive no curso do processo judicial.

Cabral e Cramer (2016) destacam que é importante atentarse ao art. 139, V, do atual CPC, recomendando que o magistrado se valha de conciliadores e mediadores para se desincumbir do dever de tentar conciliar as partes. Essa disposição é razoável e plausível, considerando que o magistrado, ao atuar juntamente como conciliador ou mediador e julgador, pode vir a constranger ou pressionar as partes nas tratativas da autocomposição. Nota-se que, embora não seja recomendável, a realização de conciliação ou mediação pelo magistrado não é vedada, entendendo-se que tal atividade é decorrência do poder que o magistrado exerce no processo.

No vigente Código de Processo Civil, dentre as normas previstas que os mediadores e conciliadores são auxiliares da justiça, art. 149 (BRASIL, 2016). Já na Seção V - Dos conciliadores e mediadores judiciais, entre os art. 165 a 175, disciplinam que os mediadores e os conciliadores, deveram ser regidos pelos princípios fundamentais que norteadores de suas funções, previstos no artigo 166 do atual CPC, quais sejam: a independência, a imparcialidade, a autonomia da vontade, a confidencialidade, a oralidade, a informalidade e a decisão informada.

Cita Guerrero (2019) que no atual o CPC, prevê treinamento para aqueles indivíduos que serão responsáveis 
por mediações e conciliações no art. 165 e seguintes. Essa iniciativa é louvável, pois a técnica processual e a técnica dos MASCs só poderão ser bem aplicadas por indivíduos que efetivamente as conheçam e o treinamento adequado.

Tartuce (2019) expõe que no art. $165, \S 3^{\circ}$, do vigente CPC, que o mediador atuará preferencialmente nos casos em que houver vínculo anterior entre as partes, assim, as auxiliará a compreender as questões e os interesses em conflito, de modo que eles possam, pelo restabelecimento da comunicação, identificar, por si próprios, soluções consensuais que gerem benefícios mútuos.

$\mathrm{Na}$ conciliação, descrito no art. $165, \S 2^{\circ}$, do Código de Processo Civil, o conciliador poderá sugerir soluções para o litigio, e preferencialmente deverá atuar caso onde não houver vínculo entre as partes.

No Artigo $166, \S 1^{\circ}$, descreve que a confidencialidade deve ser estendida a todas as informações produzidas no curso do processo, cujo o seu conteúdo não poderá ser utilizado para fim diverso daquele previsto por expressa deliberação das partes.

No artigo 167 do CPC (BRASIL, 2016), descreve que se faz necessário a criação de múltiplos cadastros de mediadores, conciliadores e câmaras privadas de conciliação e mediação. Haverá um cadastro nacional, mantido pelo Conselho Nacional de Justiça. Poderão ser criados, ainda, cadastros pelos Tribunais de Justiça estaduais e pelos Tribunais Regionais Federais. Por conseguinte, basta que seja incluída no cadastro nacional essa informação para que seja prescindível a criação de cadastros setoriais em cada tribunal.

Descrevem Almeida, Pantoja e Pelajo (2016), que no $\$ 1^{\circ}$ do artigo 167 do vigente Código de Processo Civil exige que todos os profissionais que pretendam receber causas por livre distribuição devam, obrigatoriamente, ter frequentado curso de capacitação a ser ministrado por entidades, seguindo os moldes definidos pelo Conselho Nacional de Justiça juntamente com o Ministério da Justiça. Assim, sendo requisito obrigatório dos conciliadores e mediadores a qualificação e capacitação.

No $§ 5 .^{\circ}$ do artigo 167 do $\mathrm{CPC} / 2015$, traz disposição delimitando a atuação do mediador e conciliador, ao proibir o profissional de atuar como advogado junto ao juízo onde exerce as suas funções como mediador ou conciliador. Isso porque, aquele profissional já possui certa proximidade com o órgão jurisdicional.

Comenta Didier Junior (2016) em seu caput do artigo 169, dispõe que cada tribunal elaborará uma tabela fixando os honorários dos mediadores e conciliadores, seguindo os critérios a serem fixados pelo Conselho Nacional de Justiça - CNJ. Ainda no artigo 169, mas no $\S 1^{\circ}$, do atual CPC, é autorizada que a mediação e a conciliação sejam desenvolvidas como trabalho voluntário. Com razão, o mesmo dispositivo legal ressalta que devem os mediadores e conciliadores preencher os requisitos legais. Solução diversa acabaria por criar profissionais de segunda categoria, autorizando a prestação insatisfatória de tais serviços, apenas por se tratar de trabalho voluntário, o que prejudicaria as partes envolvidas e o próprio instituto da mediação e da conciliação.

Para Almeida, Pantoja e Pelajo (2016) é possível afirmar que o atual sistema processual, ao estabelecer, em seu artigo 334, §11, do CPC, que a autocomposição obtida será reduzida a termo e homologada por sentença, permite uma da independência parcial da mediação, uma vez que os acordos obtidos deverão passar pelos olhares do juiz. Destaca-se que o acordo é uma construção das partes e que a independência do mediador não se relaciona com o resultado, mas com o método e a prática da mediação. A exigência de homologação subordina a autonomia e a independência das partes à análise do juiz, mas não a independência do mediador em si.

Almeida, Pantoja e Pelajo (2016) destaca que no $\S 4^{\circ}$ do artigo 695 do CPC prevê que na audiência, as partes deverão estar acompanhadas de seus advogados ou de defensores públicos. A participação dos advogados ou defensores públicos na mediação pode proporcionar as partes envolvidas um encaminhamento especialmente eficaz e efetivo ao conflito antes experimentado.

O Atual CPC dá o primeiro passo rumo à disseminação da cultura da mediação e conciliação, o que se mostra de extrema relevância. A forma como esse instituto será recebido e tratado pelos operadores do Direito ainda é incerto, mas promissora.

\subsection{Dificuldades e desafios dos métodos de solução de conflitos no Brasil}

As falhas do sistema judiciário devem servir de aprendizado ao seu constante aperfeiçoamento e ao trabalho cooperativo para solução adequada fora do sistema por meio da desjudicialização e humanização do judiciário, explica Barcellar (2016). Se os cidadãos, no exercício de seu direito de ação, continuam procurando o Poder Judiciário para resolver seus conflitos, é preciso potencializar isso de forma construtiva para descobrir a energia necessária ao encontro de soluções mais criativas e adequadas para cada conflito.

A criação de ambientes não adversarias de resolução de disputas consiste em um dos maiores desafios para esta política pública e para o próprio Poder Judiciário. Isto porque esta mudança envolve uma mudança de cultura de toda sociedade.

A cultura, para ser alterada, demanda amplo conhecimento do comportamento humano, no nosso caso a estrutura e vicissitudes do Poder Judiciário e seus operadores também pode ser englobado, bem como a criação de estímulos para a mudança de cultura. Naturalmente, nova atualização de procedimentos somente terá adesão se o novo sistema oferecer algo que o antigo não possuía (BRASIL, 2015).

O Poder Judiciário é indispensável para resolver problemas essenciais, em que ele é verdadeiramente o mais adequado, e será mais eficiente quando de forma integrada buscar seu funcionamento em harmonia com soluções coexistentes complementares, como as extrajudiciais, exemplo: a conciliação e a mediação.

Ensina Tartuce (2019) que o profissional do direito 
não costuma contar, em seu panorama de formação, com a habilitação para considerar meios consensuais, sendo seu estudo orientado para a abordagem conflituosa na maior parte do tempo. Assim, geralmente não tem consciência nem conhecimento sobre como mediar conflitos, o que tende a dificultar sua adesão e gerar desconfianças sobre a adequação de técnicas negociais.

Esse panorama tem mudado, diversos cursos de graduação em Direito tem incrementado em sua grade curricular sessões de mediação e conciliação por meio de seus Núcleos de Prática Jurídica.

Constitui dever do advogado, segundo o Código de Ética e Disciplina da Ordem dos Advogados do Brasil, estimular a adoção de meios consensuais entre os litigantes, prevenindo, sempre que possível, a instauração de litígios. Como destacado por Tartuce (2019), para otimizar a eficiência dos meios consensuais, a participação do advogado pode ser valiosa, o incentivo à adoção de tal meio pelo cliente e a presença na sessão propiciará aos envolvidos contar com um profissional habilitado a orientar, sanar dúvidas, conferir a viabilidade de pactos e alertar quanto a elementos úteis à sua exequibilidade.

Em termos de verba honorária, vale destacar previsão do Código de Ética da OAB em seu art. 48 § 5. ${ }^{\circ}$, descreve que é vedada, em qualquer hipótese, a diminuição dos honorários contratados em decorrência da solução do litígio por qualquer mecanismo adequado de solução extrajudicial.

Um dos maiores desafios do mediador consiste em desarmar as partes de suas defesas e acusações, e buscar cooperação na busca de soluções práticas. Assim, apresentamse a seguir algumas ferramentas para estimular as partes a construir o entendimento recíproco.

\section{Conclusão}

De acordo com as análises feitas no presente trabalho, é importante que sejam ressaltadas algumas considerações obtidas pelo estudo da temática abordada sobre a conciliação e mediação no vigente Código de Processo Civil, como meios alternativos de auto composição de tratamento de conflitos.

O Judiciário brasileiro demonstra muito empenho na promoção dos meios consensuais de resolução de disputas, tendência essa fortalecida pelas políticas públicas estimuladas pela Constituição Federal do Brasil de 1988, Resolução n ${ }^{\circ}$ 125/2010 do CNJ, pelo atual Código de Processo Civil e pela Lei de Mediação, como já discutido neste trabalho.

Há uma transformação revolucionária no Poder Judiciário Brasileiro em termos de qualidade e quantidade dos serviços judiciários, isso devido principalmente a inclusão de tecnologias e métodos mais eficientes. Com esforções o índice de pacificação das partes em conflito é com toda certeza, à profunda transformação do nosso país que substituirá a busca por uma sentença, por uma busca na pacificação dos conflitos. Isso já tem ocorrido principalmente em razão dos trabalhos realizados nos Tribunais junto com os conciliadores e mediadores capacitados.

Diante dessa mudança, necessária, de cultura para a solução de conflitos pela mediação e conciliação, tem por objetivo estimular maior compreensão recíproca, humanização dos conflitos, manutenção da relação social e, por consequência, maior realização pessoal entre os envolvidos.

A auto composição não deve ser vista, somente, como uma forma de diminuição do número de causas que tramitam no judiciário ou como técnica de aceleração dos processos. São outros os valores subjacentes às políticas públicas do tratamento adequado dos conflitos dos conflitos jurídicos: incentivo à participação do indivíduo a elaboração da norma jurídica que regulará o seu caso e o respeito a sua liberdade, concretizada no direito ao autorregramento.

A mediação e conciliação são desejáveis essencialmente porquê são mais construtivas. O desafogo vem como consequência, e não como a meta principal. Essa constatação é importante: um enfoque distorcido do problema pode levar a resultado indesejados. Vista como instrumento de administração da máquina judiciaria, a conciliação passa a ser uma preocupação com estatística. Sua recusa pelas partes direito mais do que legitimo - passa a ser vista como uma espécie de descumprimento de um dever cívico e, no processo, pode fazer com que se tome como inimigo do Estado aquele que não está disposto a abrir mão de parte do que entender ser seu direito.

Cabe ressaltar que a utilização destes métodos alternativos de resolução de conflitos, mostra-se benéfica às partes envolvidas nos conflitos, uma vez que estes serão resolvidos de forma mais célere, consensual, econômica, além é claro de forma mais confiável, pois são as próprias partes que escolhem o procedimento que irá lhes ajudar, e sobretudo a solução do litígio, reafirmando sua autonomia e responsabilidade.

Almeja-se àquilo que sonharam todos os homens, uma nova sociedade de paz em que a alteridade e empatia prevaleçam às guerras e explorações. Para isso, que se firme compromisso de jamais abandonar a ética e a lógica do amor e da fraternidade na execução de qualquer ação ou de qualquer discurso.

\section{Referências}

ALMEIDA, D.A.; PANTOJA, F.M.; PELAJO, S. A mediação no Novo Código de Processo Civil. Rio de Janeiro: Forense, 2016.

BARCELLAR, P.R. Mediação e arbitragem. São Paulo: Saraiva, 2016.

BRAGA NETO, A. Alguns aspectos relevantes sobre a mediação de conflitos. São Paulo: Revista dos Tribunais, 2004.

BRASIL. Constituição Federal de 5 de outubro de 1988. Disponível em: http://www.planalto.gov.br/ccivil_03/ constituicao/constituicao.htm. Acesso em: 22 jul. 2019.

BRASIL. Conselho Nacional de Justiça. Guia de Conciliação e Mediação Judicial: orientação para instalação de CEJUSC. Brasília/DF: Conselho Nacional de Justiça, 2015.

BRASIL. Código de Processo Civil e normas correlatas. Brasília: 
Senado Federal: Coordenação de Edições Técnicas, 2016.

CABRAL, P.A.D.; CRAMER, R. Comentários ao Novo Código de Processo Civil. Rio de Janeiro: Forense, 2016.

CELANT, J.H.P. A mediação e a conciliação como formas de responsabilidade e autonomia dos indivíduos na solução de conflitos. Itajaí: UNIVALI, 2015.

CONFERÊNCIA Especializada Interamericana sobre Direitos Humanos, pactuada em San José de Costa Rica, em 22.11.1969, ratificada pelo Brasil em 25.09.1992. Disponível em: https:// www.cidh.oas.org/basicos/portugues/c.convencao_americana. htm. Acesso em: 26 jul. 2019.

CNJ - Conselho Nacional de Justiça. Departamento de Pesquisas Judiciárias. Justiça em Números 2019. Brasília: CNJ, 2019.

CNJ - Conselho Nacional de Justiça. Conciliação. 2019 b. Disponível em: <http://www.cnj.jus.br/programas-e-acoes/ forum-da-saude/audiencia--publica/356-geral/125-conciliacao $>$. Acesso em: 1 mar. 2019.
DIDIER JUNIOR, F. Curso de direito processual civil: introdução ao direito processual civil: parte geral e processo de conhecimento. Salvador: Jus Podivm, 2016.

GUERRERO, F.L. Os métodos de solução de conflitos e o Processo Civil. 2019. Disponível em: https://integrada.minhabiblioteca. com.br/\#/books/978-85-970-0367-3/. Acesso em: 8 jun. 2019.

GUILHERME, L.F.V.A. Manual de arbitragem e mediação: conciliação e negociação. São Paulo: Saraiva, 2018.

PINHO, B.H.D. Direito processual civil contemporâneo: teoria geral do processo. 2019. Disponível em: https:/integrada. minhabiblioteca.com.br/\#/books/9788553600502/. Acesso em: 14 maio 2019.

PUCCI, A.N. Mercosul: seus efeitos jurídicos, econômicos e políticos nos estados-membros. Porto Alegre: Livraria do Advogado, 1997.

TARTUCE, F. Mediação nos conflitos civis. Rio de Janeiro: Forense, 2019. 